\title{
Hydroxychloroquine Attenuates Myocardial Ischemic and Post-ischemic Reperfusion Injury by Inhibiting the Toll-like Receptor 9 - Type I Interferon Pathway
}

\section{Katherine M. Marsh}

University of Virginia Health System: UVA Health https://orcid.org/0000-0003-1927-6210

\section{Radhika Rastogi}

University of Virginia Health System: UVA Health

\section{Aimee Zhang}

University of Virginia Health System: UVA Health

\section{Di Wu}

University of Virginia Health System: UVA Health

Irving L. Kron

University of Virginia Health System: UVA Health

Zequan Yang ( $D$ ZY6B@hscmail.mcc.virginia.edu )

University of Virginia Health System: UVA Health https://orcid.org/0000-0001-9993-680X

\section{Research article}

Keywords: Myocardial infarction, ischemia, reperfusion injury, Toll-like Receptor 9, Type I Interferon, hydroxychloroquine

Posted Date: August 30th, 2021

DOl: https://doi.org/10.21203/rs.3.rs-824354/v1

License: (c) (i) This work is licensed under a Creative Commons Attribution 4.0 International License. Read Full License 


\section{Abstract}

Background: Hydroxychloroquine (HCQ) is a toll-like receptor (TLR) 7 and 9 inhibitor that has been used clinically for its anti-inflammatory effects. We hypothesized that HCQ would attenuate myocardial ischemia/reperfusion (IR) injury by inhibiting the TLR9 - type I interferon (IFN-I) pathway.

Methods: The left coronary artery of wild-type (WT) C57BL/ 6 and congenic TLR9 ${ }^{-/-}$mice was occluded for 40 minutes to induce myocardial ischemia, with or without 60 minutes of subsequent reperfusion ( $40^{\prime} / 0^{\prime}$ or $\left.40^{\prime} / 60^{\prime}\right)$. Treatment with TLR9 inhibitors ODN-2088 or HCQ, or with TLR9 agonist ODN-1826 was administered either before ischemia or before reperfusion to determine effect on infarct size (IS). Myocardial IS as a percentage of risk region was measured by TTC-Blue staining. After $40^{\prime} / 0^{\prime}$, cardiac perfusate (CP) was collected from harvested hearts and used to treat either intact WT mice after 20 minutes of ischemia or isolated splenocytes. IFNa and IFNb levels were measured in plasma and splenocyte culture supernatant, and HMGB1 and cfDNA levels were measured in CP.

Results: After $40^{\prime} / 60^{\prime}$ of IR, WT mice treated with HCQ or ODN-2088 had significantly reduced IS. Both $40^{\prime} / 0^{\prime}$ ischemic injury and 40'/60' IR injury were similarly attenuated in TLR9-/- mice and HCQ-treated WT mice. HCQ did not further reduce IS in TLR9 ${ }^{-/-}$mice. TLR9 ${ }^{-/-}$and HCQ-treated WT mice had significantly lower IFNa and IFNb in CP after 40'/0' ischemic injury and in plasma after 40'/60' IR. 40'/0' CP or ODN1826 significantly increased IS in WT mice undergoing 20'/60' IR. CP-treated WT splenocytes produced significantly higher IFNa and IFNb in culture supernatant at 2 hours. HCQ significantly reduced the production of IFNa and IFNb.

Conclusions: The TLR9 - IFN-I-mediated inflammatory response is an important contributor to both ischemic and post-ischemic myocardial IR injury. HMGB1 and cfDNA released from ischemic myocardium activated the intra-myocardial TLR9 - IFN-I inflammatory pathway during ischemia and the extra-myocardial TLR9 - IFN-I inflammatory pathway during reperfusion. Hydroxychloroquine reduces production of IFN-I and attenuates myocardial IR injury, likely by inhibiting the TLR9 - IFN-I pathway.

\section{Background}

Immune-mediated myocardial injury has been implicated in a broad range of cardiac diseases including ischemic heart disease ${ }^{1-4}$. Mounting clinical evidence suggests that acute myocardial infarction (MI), myocardial ischemia/reperfusion (IR) injury, and post-MI left ventricular (LV) remodeling are all associated with enhanced immune responses ${ }^{4-9}$. Activation of the innate immune-mediated inflammatory response occurs when damage-associated molecular patterns (DAMPs) released from the damaged cardiomyocytes interact with pattern recognition receptors (PRRs). Among PRRs, Toll-Like Receptors (TLR) in particular have been recognized as key elements to mediate the inflammatory response in acute $\mathrm{MI}$ and myocardial IR injury ${ }^{3,10}$. Once released into the bloodstream during postischemic reperfusion, DAMPs such as cell-free DNA (cfDNA) and high mobility group box-1 (HMGB1) activate the receptor for advanced glycation endproducts (RAGE) - TLR9 pathway to invoke an 
inflammatory response ${ }^{11,12}$. cfDNA additionally activates plasmacytoid dendritic cells ( $\left.p D C s\right)$ to release type I interferons (IFN-Is) including interferon alpha and beta (IFNa and IFN $\beta$ ). In turn, IFN-Is mediate postischemic reperfusion injury ${ }^{13}$.

The anti-malarial drug hydroxychloroquine (HCQ) is a TLR7 and TLR9 antagonist ${ }^{14}$ that has been used as an immunomodulator to treat autoimmune diseases such as systemic lupus erythematosus ${ }^{15-17}$ and rheumatoid arthritis ${ }^{18}$. HCQ exhibits potent anti-inflammatory properties by inhibiting TLR9 and IFN-ls inside $\mathrm{pDCs}{ }^{17}$. HCQ has also demonstrated protection against renal ${ }^{19}$, skeletal muscle ${ }^{20}$, and myocardial ${ }^{21}$ ischemia/reperfusion injury (IRI) when administered before onset of ischemia, but the role of HCQ after the onset of myocardial infarction remains unknown. During post-ischemic reperfusion injury, the pDC-IFN-I pathway has been shown to mediate the inflammatory response (JAHA). Thus, it is worthwhile to evaluate the role of HCQ in protecting the heart against both acute MI and IR injury.

We hypothesized that the TLR9 - IFN-I pathway is activated during acute MI and mediates both ischemic myocardial injury and post-ischemic reperfusion injury. Since HCQ inhibits the TLR9 - IFN-I pathway, administration is expected to attenuate the inflammatory response and associated post-ischemia reperfusion injury. If administered before the onset of ischemia it should additionally attenuate ischemic injury from $\mathrm{Ml}$.

\section{Methods}

This study complied with the 2011 Guide for the Care and Use of Laboratory Animals, 8th edition as recommended by the U.S. National Institutes of Health ensuring that all animals received humane care. The University of Virginia Animal Care and Use Committee reviewed and approved the study protocol (\#3943-08-18).

\section{Animals and Materials}

C57BL/6 wild type (WT) mice and TLR9-/- mice (male, aged 9-14 weeks, purchased from The Jackson Laboratory, Bar Harbor, ME) were used in the study. HCQ was purchased from ThermoFisher. Oligodeoxynucleotides (ODN)-1826, ODN-2088, and ODN-2088 negative control were purchased from InvivoGen. Anti-HMGB1 antibodies were purchased from Abcam. IFNa and IFN $\beta$ antibodies were purchased from ThermoFisher.

\section{Experimental Groups}

\section{Ischemia-only $\left(40^{\prime} / 0^{\prime}\right)$}

WT and TLR9 ${ }^{-/-}$mice were treated with either phosphate buffered saline (PBS) $(2 \mu \mathrm{l} / \mathrm{g})$ or high dose HCQ $(20 \mu \mathrm{g} / \mathrm{g}) 5$ minutes prior to ischemia. The mice then underwent 40 minutes of ischemia without reperfusion (Fig. 1). Cardiac perfusate (CP) was collected from these mice before TTC-Blue staining, discussed further below. 


\section{IRI Pre-Ischemic Treatment (40'/60')}

WT mice were pre-treated 5 minutes before prior to left coronary artery (LCA) occlusion with either high dose HCQ $(20 \mu \mathrm{g} / \mathrm{g})$, ODN-2088 negative control $(0.6 \mu \mathrm{g} / \mathrm{g})$, or ODN-2088 $(0.6 \mu \mathrm{g} / \mathrm{g})$. Mice then underwent 40 minutes of ischemia and 60 minutes of reperfusion (Fig. 1).

\section{IRI Pre-Reperfusion Treatment $\left(40^{\prime} / 60^{\prime}\right.$ or $\left.20^{\prime} / 60^{\prime}\right)$}

WT mice underwent 40 minutes of ischemia, followed by treatment with either $2 \mu \mathrm{l} / \mathrm{g}$ body weight PBS (control), or varied dosages of HCQ ( $5 \mu \mathrm{g}, 10 \mu \mathrm{g}$, or $20 \mu \mathrm{g} / \mathrm{g}$ body weight) as an intravenous bolus 5 minutes before reperfusion. Lastly, the mice underwent 60 minutes of reperfusion (Fig. 1). A separate group of WT mice underwent 20 minutes of ischemi and then treatment 5 minutes before reperfusion with either PBS (control, $2 \mu \mathrm{l} / \mathrm{g}$ ), 40'/0' CP $(2 \mu \mathrm{l} / \mathrm{g}$ ), or ODN-1826 $(10 \mu \mathrm{g} / \mathrm{g})$. The mice then underwent 60 minutes of reperfusion (Fig. 1).

\section{Ex-Vivo Experiment}

CP was collected in WT mice that underwent 40 minutes of LCA occlusion without reperfusion $\left(40^{\prime} / 0^{\prime}\right)$. Isolated WT splenocytes were treated either with PBS, CP, or CP plus HCQ, discussed further below. After 2 hours, IFNa and IFN $\beta$ levels were measured in the cell culture supernatant (Fig. 1).

\section{Myocardial IRI}

Myocardial infarction was induced in intact mice as previously described ${ }^{4,22,23}$. Briefly, anesthetized mice (Avertin $250 \mathrm{mg} / \mathrm{kg}$ with an additional $125 \mathrm{mg} / \mathrm{kg}$ dose every 30 minutes intraperitoneally) were placed in a supine position on a heating pad, orally intubated with a PE-60 tube, and mechanically ventilated at a tidal volume of $10 \mu \mathrm{l} / \mathrm{g}$ and rate of 130 stroke/minute (MiniVent Ventilator, Harvard Apparatus, Holliston, MA). A left thoracotomy was performed by cutting the left 3rd and 4th ribs and intercostal muscles to expose the heart. An 8 - 0 Prolene suture was passed underneath the LCA at the level of the lower edge of the left atrium and tied over a piece of PE-50 tubing to occlude the LCA for 20 or 40 minutes. Successful LCA occlusion was confirmed by color change in the region at risk. Reperfusion was achieved by removing the tubing. A volume of $1-1.5 \mathrm{ml} 5 \%$ dextrose was given intraperitoneally to replace insensible losses during the operation. Core body temperature was monitored throughout the operation with a rectal thermocouple interfaced to a digital thermometer (Barnant Co, Barrington, IL) and maintained between $36.5-37.5^{\circ} \mathrm{C}$.

\section{Determination of Infarct Size}

Following LCA occlusion with or without reperfusion, mice were euthanized under deep anesthesia. The heart was isolated and ascending aorta cannulated with a blunt 23-gauge needle. The heart was sequentially perfused with $3 \mathrm{ml}$ of PBS ( $\mathrm{pH}=7.4)$ and $3 \mathrm{ml}$ 1\% 2,3,5-Triphenyltetrazolium chloride (TTC) in PBS at $37^{\circ} \mathrm{C}$. The LCA was then re-occluded by retying the LAD-encircling suture, and the heart was perfused with 0.5-1.0 ml 10\% Phthalo Blue (Heubach Ltd, Fairless Hills, PA) to delineate the non-ischemic region. The heart was then frozen and trimmed of the right ventricle and atria. The left ventricle was cut 
into 5-7 slices, which were fixed in 10\% neutral buffered formalin solution. Each slice was weighed and photographed. The sizes of the non-ischemic area, the area at risk, and the infarct area were calculated as a percentage of the corresponding area multiplied by the weight of the slice as previously reported 4,22-26. For example, myocardial infarct size (IS) was reported as a percentage of risk region (RR, \% of LV).

\section{Cardiac perfusate (CP) and splenocyte cell culture Acquisition of cardiac perfusate (CP)}

Following 40 minutes of ischemia without reperfusion $\left(40^{\prime} / 0^{\prime}\right)$, hearts were harvested and ascending aorta cannulated with a 23-gauge needle. Hearts were then perfused with $500 \mu \mathrm{PBS}\left(\mathrm{pH}=7.4\right.$ at $\left.37^{\circ} \mathrm{C}\right)$ for 4 cycles. The $\mathrm{CP}$ was collected and centrifuged at $3000 \mathrm{rpm}$ for 20 minutes to discard cellular sediments. CP levels of cfDNA and HMGB1 were evaluated using Nanodrop and Western Blot (AntiHMGB1 antibody purchased from Abcam) $)^{11,12}$

\section{Splenocyte culture with stimulation by CP}

The spleen was dissociated into a single-cell suspension using PBS supplemented with $10 \%$ fetal bovine serum in GentleMACs tubes (Miltenyi Biotec). Red blood cells were lysed by resuspending splenic cells in ammonium chloride-Tris buffer and incubating at room temperature for 8 minutes. Leukocytes were collected following centrifugation and washed twice in PBS. The splenic leukocytes were resuspended in PBS, enriched to $2 \times 10^{6} / \mu$ land incubated in 6-well plates (BD Company) at a concentration of $8.2 \times 10^{6}$ cells in $1.2 \mathrm{ml}$ of culture media per well. Then, $100 \mu \mathrm{l}$ of PBS or $40^{\prime} / 0^{\prime} \mathrm{CP}$ (containing $\left.8.1 \mu \mathrm{g} / \mathrm{ml} \mathrm{cfDNA}\right)$, respectively, were added to 4 -well ( $n=4$ /group) cell culture plates and incubated for 2 hours. Another group of splenocytes were pretreated with HCQ $(92 \mu \mathrm{M})$ administered 30 minutes before the addition of $40^{\prime} / 0^{\prime} \mathrm{CP}$ and then incubated for 2 hours. Following the incubation period, supernatants were collected and the levels of IFNa and IFN $\beta$ were measured by Western blot. Live counts of splenic leukocytes were measured using a fluorescence automated cell counter (Cellometer K2, Nexcelom. Lawrence, MA).

\section{Measurement of IFNa, IFN $\beta$, HMGB1 and cfDNA}

Plasma and CP levels of IFNa and IFN $\beta$ were determined using an ELISA kit (Bio-Rad Laboratories). Levels of IFNa and IFN $\beta$ in the supernatant of splenic leukocyte cultures and levels of HMGB1 in CP were evaluated using Western Blot (ThermoFisher). Levels of cfDNA in CP were measured using Nanodrop.

\section{Statistical Analysis}

Comparisons between groups were performed with one-way analysis of variance with Bonferroni's correction for multiple comparisons and unpaired Student's t-test. Prism 7 (GraphPad Software Inc., La Jolla, CA) was used to perform statistical calculations. Data are presented as mean \pm standard error of the mean, with a $p$-value $<0.05$ indicating statistical significance.

\section{Results}




\section{TLR9 and HCQ in myocardial ischemic injury}

For mice that underwent 40 minutes of ischemia without reperfusion $\left(40^{\prime} / 0^{\prime}\right)$, ischemic risk region (RR, as percentage of LV mass) was comparable among all groups. Infarct size (IS) was measured as percentage of RR. WT control mice had an IS of $23 \pm 4$ whereas treatment with HCQ, as a $20 \mu \mathrm{g} / \mathrm{g}$ intravenous bolus administered before occlusion, attenuated IS to $8 \pm 2$ vs. control $p<0.05)$. In TLR9-/- mice, IS was $11 \pm 2$, a $50 \%$ reduction from WT control $(p<0.05$, Fig. $2 A)$. Levels of IFNa and IFN $\beta$ in CP were significantly lower in HCQ-treated WT mice and TLR9 ${ }^{-/-}$mice than WT control mice (Fig. 2B). Cell-free DNA and HMGB1 in CP were also significantly lower in HCQ-treated WT mice and TLR9 ${ }^{-/-}$mice than WT control mice (Fig. 3).

\section{TLR9 and HCQ in post-ischemic reperfusion injury}

When treated immediately prior to ischemia (IRI pre-ischemic treatment), IS after 60 minutes of reperfusion was significantly attenuated to $26 \pm 8$ in $\mathrm{TLR}^{-/-}$mice, a $>40 \%$ reduction compared to WT control mice $(p<0.05)$. HCQ treatment $(20 \mu \mathrm{g} / \mathrm{g})$ did not further reduce the IS in TLR9-/- mice (Fig. 4A \& 4B). Pre-treated WT mice with ODN-2088 or high dose HCQ similarly attenuated IS ( $28 \pm 4$ or $26 \pm 2$, respectively, vs. corresponding control - ODN negative or PBS control ( $50 \pm 4 \%$ or $53 \pm 4 \%, p<0.05$. Figure 4C). RR was comparable among the control and treated groups (right column in Fig. 4C).

When treated immediately prior to reperfusion (IRI pre-reperfusion treatment), RR was comparable among the control and 3 HCQ-treated groups $(5 \mu \mathrm{g}, 10 \mu \mathrm{g}$, or $20 \mu \mathrm{g} / \mathrm{g})$ following 40 minutes of ischemia and 60 minutes of reperfusion $\left(40^{\prime} / 60^{\prime}\right)$. IS was significantly reduced in all HCQ-treated mice (low dose HCQ $33 \pm$ 3 , moderate dose $33 \pm 6$, and high dose $22 \pm 4$, vs. control $53 \pm 3, p<0.05$ ). High dose HCQ-treated mice tended to have a smaller IS compared to the low and moderate dose HCQ-treated mice, but the difference did not reach statistical significance (Fig. 5A). In control mice, plasma levels of IFNa and IFN $\beta$ were significantly elevated at the end of 60 minutes of reperfusion. Levels of IFNa and IFN $\beta$ in HCQ-treated mice (moderate dose) were significantly lower than control mice but remained higher than the control mice (Fig. 5B). After 20 minutes of ischemia and 60 minutes of reperfusion $\left(20^{\prime} / 60^{\prime}\right)$ with IRI prereperfusion treatment, there were no difference in RR among all groups. The IS in WT control mice was 4 \pm 1 . CP and ODN-1826 significantly exacerbated IS to $14 \pm 3$ and $21 \pm 4$ respectively ( $p<0.05$ vs. control). There was no statistical difference between CP- and ODN-1826-treated groups (Fig. 6).

\section{Cardiac perfusate from ischemic hearts stimulates type I interferon responses}

Splenic leukocytes were incubated in 6-well BD plates at a final concentration of $6.37 \times 10^{6}$ cells in $1.3 \mathrm{ml}$ of culture media plus treatment per well. After 2 hours of incubation, the splenocyte count dropped similarly in each group by an average of $13 \%$. There were $5.56 \pm 0.08 \times 10^{6}$ living splenocytes remaining with PBS control, $5.73 \pm 0.05 \times 10^{6}$ with CP alone, and $5.34 \pm 0.17 \times 10^{6}$ with CP plus HCQ $(p=N S$ among 
the 3 different treatments). CP stimulated splenic leukocytes to secrete IFNa and IFN $\beta$. The increases in IFNa and IFN $\beta$ levels were were reduced by treatment with HCQ (Fig. 7).

\section{Discussion}

Our previous studies have demonstrated that ischemically-injured cardiomyocytes release DAMPs into the circulation which activate the pDC - IFN-I pathway, exacerbate the inflammatory response, and induce post-ischemic reperfusion injury. The present study further demonstrates that the inflammatory response is triggered by the TLR9 - IFN-I pathway both inside ischemic myocardium and systemically during post-ischemic reperfusion. HCQ exerts cardioproctective effects against both initial ischemic injury and subsequent post-ischemic reperfusion injury by inhibiting the TLR9 - IFN-I pathway.

Total myocardial infarction during ischemia and post-ischemic reperfusion is a function of ischemic infarction; i.e. there will be no cardiomyocytic necrosis during reperfusion if there is no initial ischemic myocardial necrosis ${ }^{11,27}$. Myocardial ischemic injury has been investigated, to some extent, by isolated Langendorff heart models as they demonstrate de novo inflammatory responses inside the heart. Hypoxia-injured cardiomyocytes release DAMPs including mitochondrial DNA, which activate the TLR9 IFN-I pathway and mediate the inflammatory response inside the myocardium ${ }^{28}$. In vivo myocardial IRI activates not only the intrinsic myocardial inflammatory response during ischemia, but also the extrinsic inflammatory responses during post-ischemic reperfusion, which collectively culminates in overall intramyocardial inflammation $4,11,22$. This helps explain why HCQ has demonstrated protection against myocardial IR injury when administered before the onset of ischemia ${ }^{21}$. In the current study, we found that both IFNa and IFN $\beta$ levels were significantly elevated in 40'/0' CP (Fig. 2), 40'/60' plasma (Fig. 5) and $40^{\prime} / 0^{\prime}$ CP-treated splenocytes (Fig. 7). Both intrinsic deficiency of TLR9 (TLR9 ${ }^{-/-}$mice) or blocking the effects of TLR9 (HCQ treatment) significantly reduced the production of IFNa and IFN $\beta$. These results demonstrate that cfDNA and HMGB1 released from ischemically-injured cardiomyocyes activates the TLR9 - IFN-I pathway both inside the myocardium during ischemia and outside the myocardium during post-ischemic reperfusion. During ischemia, cfDNA/HMGB1 activates the TLR9 - IFN-I pathway, which leads to more ischemic injury and further cfDNA/HMGB1 release in addition to hypoxic injury, resulting in a vicious cycle that exacerbates ischemic myocardial injury. Deficiency of TLR9 or HCQ treatment before ischemia significantly reduced the production of IFNa and IFN $\beta$ (Fig. 2B) and attenuated ischemic myocardial infarction (Fig. 2A). Taken together, these results demonstrated that TLR9 - IFN-I pathway inside myocardium was activated during ischemia and mediated ischemic myocardial infarction.

It has been demonstrated that post-ischemic reperfusion injury is induced by inflammatory responses $4,11,12,22-24,27$ that are triggered by DAMPs released from ischemically-injured cardiomyocytes ${ }^{11,12,29}$. DAMPs thus are thought to exacerbate myocardial infarction during reperfusion ${ }^{11}$. We have demonstrated that two important DAMPs in particular, cfDNA and HMGB1, play a critical role in mediating inflammatory responses during reperfusion. Specifically, HMGB1 binds to RAGEs of inflammatory cells and facilitates intracellular migration of $\operatorname{cfDNA}^{11,12}$. Increased levels of cytosolic 
cfDNA then activates TLR9 and enhances production of IFN-Is ${ }^{13}$. The role of TLR9 in mediating ischemia/reperfusion injury has been explored in the liver ${ }^{30}$ and heart ${ }^{28,31}$. In the current study, we found that TLR9 ${ }^{-/-}$mice had significantly smaller IS following 40'/60' IR injury compared to WT control mice; HCQ failed to further decrease the IS in TLR9 ${ }^{-/-}$mice (Fig. 4A\&B). The role of TLR9 was further defined by using the TLR9 antagonists ODN-2088 and HCQ. Administration of a TLR9 antagonist (ODN-2088 or high-dose HCQ) before occlusion of the LCA similarly attenuated myocardial IS after $40^{\prime} / 60^{\prime}$ IR injury in WT mice (Fig. 4C). Interestingly, ODN-2088 failed to attenuate IS if administered before reperfusion (data not shown). However, HCQ administered either before or after LCA occlusion similarly attenuated IS (Fig. 5A and 4C). HCQ significantly decreased the plasma level of IFNa and IFNß (Fig. 5B), again supporting its inhibitory effects on the TLR9 - IFN-I pathway.

We further defined the role of TLR9 in mediating myocardial IRI with the use of a selective TLR9 agonist, ODN-1826. ODN-1826 and 40'/0' WT CP significantly exacerbated IS in WT mice that underwent 20'/60' IRI (Fig. 6). Our results are consistent with a recent report demonstrating that ODN-1826 increases myocardial IRI ${ }^{31}$. WT 40'/0' CP contained high levels of cfDNA and HMGB1 (Fig. 3). We have demonstrated that cfDNA and HMGB1 in CP trigger the inflammatory response by activating the RAGETLR9 pathway ${ }^{11,12}$. Using $40^{\prime} / 0^{\prime} \mathrm{CP}$ to treat isolated splenocytes, we found that CP stimulated splenocytes to secrete IFNa and IFN $\beta$ (Fig. 7). These results further ellucidate the role of the TLR9 - IFN-I pathway in mediating myocardial IRI.

There are multiple limitations to this study. Though HCQ was recently found to inhibit both TLR7 and TLR9, the role of TLR7 was not directly studied in this set of experiments. This might help to explain why ODN-2088 failed to attenuate IS when administered before reperfusion. However, the role of TLR7 in myocardial ischemia and IR injury may be less significant than TLR9 given that IS in TLR9-/- mice did not change with administration of HCQ. There are additional limitations with the clinical applicability of pre-ischemic treatments in particular. Treatment with HCQ before the onset of ischemia could likely protect the heart both during ischemia and during post-ischemic reperfusion. However, this is clinically not applicable unless patients are already taking HCQ regularly for another indication. Additionally, the dose required for attenuation of ischemia and IR injury may be different than doses used in current practice. In the present study, high-dose HCQ tended to have the most significant impact on IS, which raises concerns about toxicity once translated clinically. There are numerous cardiovascular, renal, and metabolic effects that can be detrimental with high levels of $\mathrm{HCQ}^{32}$. Regarding the mode of administration, HCQ has previously been reported to be cardioprotective against myocardial IRI when administered orally for several days before the $\mathrm{IR}^{21}$. However, all experiments in this study utilized intravenous HCQ. Thus, further research is required to determine the appropriate dosage of HCQ as well as the ideal mode of administration.

\section{Conclusions}


TLR9 - IFN-I-mediated inflammatory response contributes importantly to both ischemic and postischemic myocardial injury. HMGB1 and cfDNA released from ischemic myocardium activated the intramyocardial TLR9 - IFN-I inflammatory pathway during ischemia and extra-myocardial TLR9 - IFN-I inflammatory pathway during reperfusion. Hydroxychloroquine reduces production of IFN-I and attenuates myocardial IRI, likely by inhibiting TLR9.

\section{Abbreviations}

MI

Myocardial infarction

$\mathrm{IR}$

Ischemia/reperfusion

LV

Left ventricular

DAMPs

Damage-associated molecular patterns

PRRs

Pattern recognition receptors

TLR

Toll-Like Receptors

cfDNA

Cell-free DNA

HMGB1

High mobility group box-1

RAGE

Receptor for advanced glycation endproducts

pDCs

Plasmacytoid dendritic cells

IFN-Is

Type I interferons

IFNa

Interferon alpha

IFN $\beta$

Interferon beta

HCQ

Hydroxychloroquine

IRI

Ischemia/reperfusion injury

WT

Wild type 
ODN

Oligodeoxynucleotides

PBS

Phosphate buffered saline

CP

Cardiac perfusate

LCA

Left coronary artery

IS

Infarct size

RR

Risk region

\section{Declarations}

- Ethics approval and consent to participate: The University of Virginia Animal Care and Use Committee reviewed and approved the study protocol (\#3943-08-18)

- Consent for publication: Not applicable

- Availability of data and material: The data used in the current study available from the corresponding author on reasonable request

- Competing interests: The authors declare that they have no competing interests

- Funding: This work was supported in part by the National Heart, Lung and Blood Institute (NHLBI) grants R01HL130082, the University of Virginia George A. Beller, M.D. Research Award (to Yang), a T32HL007849 (to Kron), and a T32HL007849-21A1 (to Marsh and Rastogi).

- Authors' contributions: Conceptualization, Z.Y., I.K.; methodology, Z.Y., A.Z., and D.W..; formal analysis, K.M. and A.Z.; investigation, K.M., R.R. and A.Z.; data curation, D.W. and Z.Y.; writingoriginal draft preparation, K.M., R.R. and Z.Y.; writing-review and editing, K.M., R.R., and A.Z.; supervision, Z.Y.; funding acquisition, Z.Y. and I.K.

- Acknowledgements: Not applicable

\section{References}

1. Barry WH. Mechanisms of immune-mediated myocyte injury. Circulation. 1994;89(5):2421-32.

2. Knowlton KU. The immune response following myocardial infarction: a role for T-cell-mediated myocyte damage. J Mol Cell Cardiol. 2000;32(12):2107-10.

3. Gentek R, Hoeffel G. The Innate Immune Response in Myocardial Infarction, Repair, and Regeneration. Adv Exp Med Biol. 2017;1003:251-72.

4. Yang Z, Day Y-J, Toufektsian M-C, et al. Myocardial infarct-sparing effect of adenosine A2A receptor activation is due to its action on CD4 + T lymphocytes. Circulation. 2006;114(19):2056-64. 
5. Elahi AW, Vijayakumar AN, Lichstein E, Mokhtarian F. Interplay of antibody and T cell responses in acute myocardial infarction. J Lab Clin Med. 2001;138(2):112-8.

6. Blum A, Sclarovsky S, Rehavia E, Shohat B. Levels of T-lymphocyte subpopulations, interleukin-1 beta, and soluble interleukin-2 receptor in acute myocardial infarction. Am Heart J. 1994;127(5):1226-30.

7. Matsumori A, Furukawa Y, Hashimoto T, et al. Plasma levels of the monocyte chemotactic and activating factor/monocyte chemoattractant protein- 1 are elevated in patients with acute myocardial infarction. J Mol Cell Cardiol. 1997;29(1):419-23.

8. Parissis JT, Adamopoulos S, Venetsanou KF, Mentzikof DG, Karas SM, Kremastinos DT. Serum profiles of $\mathrm{C}-\mathrm{C}$ chemokines in acute myocardial infarction: possible implication in postinfarction left ventricular remodeling. J Interferon Cytokine Res. 2002;22(2):223-9.

9. Zimmer A, Bagchi AK, Vinayak K, Bello-Klein A, Singal PK. Innate immune response in the pathogenesis of heart failure in survivors of myocardial infarction. Am J Physiol Heart Circ Physiol. 2019;316(3):H435-45.

10. Vilahur G, Badimon L. Ischemia/reperfusion activates myocardial innate immune response: the key role of the toll-like receptor. Front Physiol. 2014;5:496.

11. Tian Y, Charles EJ, Yan Z, et al. The myocardial infarct-exacerbating effect of cell-free DNA is mediated by the high-mobility group box 1-receptor for advanced glycation end products-Toll-like receptor 9 pathway. J Thorac Cardiovasc Surg. 2019;157(6):2256-69 e2253.

12. Tian Y, Pan D, Chordia MD, French BA, Kron IL, Yang Z. The spleen contributes importantly to myocardial infarct exacerbation during post-ischemic reperfusion in mice via signaling between cardiac HMGB1 and splenic RAGE. Basic Res Cardiol. 2016;111(6):62.

13. Lai L, Zhang A, Yang B, Charles EJ, Kron IL, Yang Z. Plasmacytoid Dendritic Cells Mediate Myocardial Ischemia/Reperfusion Injury by Secreting Type I Interferons. J Am Heart Assoc. 2021;10(15):e020754.

14. Torigoe M, Sakata K, Ishii A, Iwata S, Nakayamada S, Tanaka Y. Hydroxychloroquine efficiently suppresses inflammatory responses of human class-switched memory B cells via Toll-like receptor 9 inhibition. Clin Immunol. 2018;195:1-7.

15. Willis R, Seif AM, McGwin G Jr, et al. Effect of hydroxychloroquine treatment on pro-inflammatory cytokines and disease activity in SLE patients: data from LUMINA (LXXV), a multiethnic US cohort. Lupus. 2012;21(8):830-5.

16. Costedoat-Chalumeau N, Galicier L, Aumaitre $\mathrm{O}$, et al. Hydroxychloroquine in systemic lupus erythematosus: results of a French multicentre controlled trial (PLUS Study). Ann Rheum Dis. 2013;72(11):1786-92.

17. Sacre K, Criswell LA, McCune JM. Hydroxychloroquine is associated with impaired interferon-alpha and tumor necrosis factor-alpha production by plasmacytoid dendritic cells in systemic lupus erythematosus. Arthritis Res Ther. 2012;14(3):R155. 
18. Schrezenmeier E, Dorner T. Mechanisms of action of hydroxychloroquine and chloroquine: implications for rheumatology. Nat Rev Rheumatol. 2020;16(3):155-66.

19. Tang TT, Lv LL, Pan MM, et al. Hydroxychloroquine attenuates renal ischemia/reperfusion injury by inhibiting cathepsin mediated NLRP3 inflammasome activation. Cell Death Dis. 2018;9(3):351.

20. Edwards NJ, Hwang C, Marini S, et al. The role of neutrophil extracellular traps and TLR signaling in skeletal muscle ischemia reperfusion injury. FASEB J. 2020;34(12):15753-70.

21. Bourke L, McCormick J, Taylor V, et al. Hydroxychloroquine Protects against Cardiac Ischaemia/Reperfusion Injury In Vivo via Enhancement of ERK1/2 Phosphorylation. PLoS One. 2015;10(12):e0143771.

22. Tian Y, French BA, Kron IL, Yang Z. Splenic leukocytes mediate the hyperglycemic exacerbation of myocardial infarct size in mice. Basic Res Cardiol. 2015;110(4):39.

23. Yang Z, Day $Y-J$, Toufektsian $M-C$, et al. Infarct-sparing effect of $A 2 A$-adenosine receptor activation is due primarily to its action on lymphocytes. Circulation. 2005;111(17):2190-7.

24. Yang Z, Zingarelli B, Szabo C. Crucial role of endogenous interleukin-10 production in myocardial ischemia/reperfusion injury. Circulation. 2000;101(9):1019-26.

25. Yang Z, Bove CM, French BA, et al. Angiotensin II type 2 receptor overexpression preserves left ventricular function after myocardial infarction. Circulation. 2002;106(1):106-11.

26. Cerniway RJ, Yang Z, Jacobson MA, Linden J, Matherne GP. Targeted deletion of A(3) adenosine receptors improves tolerance to ischemia-reperfusion injury in mouse myocardium. Am J Physiol Heart Circ Physiol. 2001;281(4):H1751-8.

27. Yang Z, Linden J, Berr S, Kron I, Beller G, French B. Timing of adenosine 2 A receptor stimulation relative to reperfusion has differential effects on infarct size and cardiac function as assessed in mice by MRI. Am J Physiol Heart Circ Physiol. 2008;295:H2328-35.

28. Kitazume-Taneike R, Taneike M, Omiya S, et al. Ablation of Toll-like receptor 9 attenuates myocardial ischemia/reperfusion injury in mice. Biochem Biophys Res Commun. 2019;515(3):442-7.

29. Oka T, Hikoso S, Yamaguchi O, et al. Mitochondrial DNA that escapes from autophagy causes inflammation and heart failure. Nature. 2012;485(7397):251-5.

30. Bamboat ZM, Balachandran VP, Ocuin LM, Obaid H, Plitas G, DeMatteo RP. Toll-like receptor 9 inhibition confers protection from liver ischemia-reperfusion injury. Hepatology. 2010;51(2):621-32.

31. Xie L, He S, Kong N, et al. Cpg-ODN, a TLR9 Agonist, Aggravates Myocardial Ischemia/Reperfusion Injury by Activation of TLR9-P38 MAPK Signaling. Cell Physiol Biochem. 2018;47(4):1389-98.

32. Lebin JA, LeSaint KT. Brief Review of Chloroquine and Hydroxychloroquine Toxicity and Management. West J Emerg Med. 2020;21(4):760-3.

\section{Figures}




\section{Figure 1.}

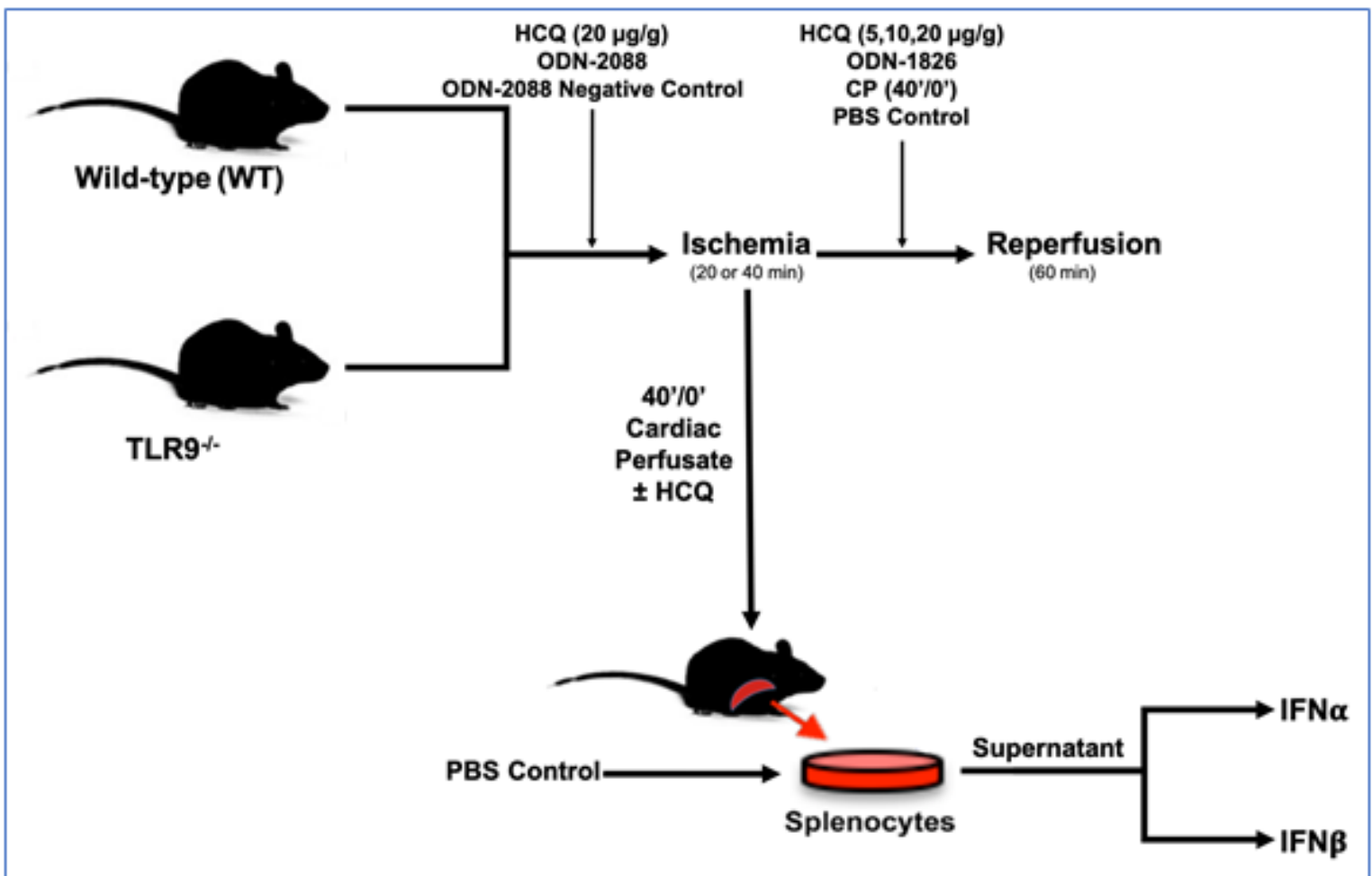

Figure 1

Cardiac perfusate (CP) was collected from these mice before TTC-Blue staining, discussed further below. 


\section{Figure 2.}
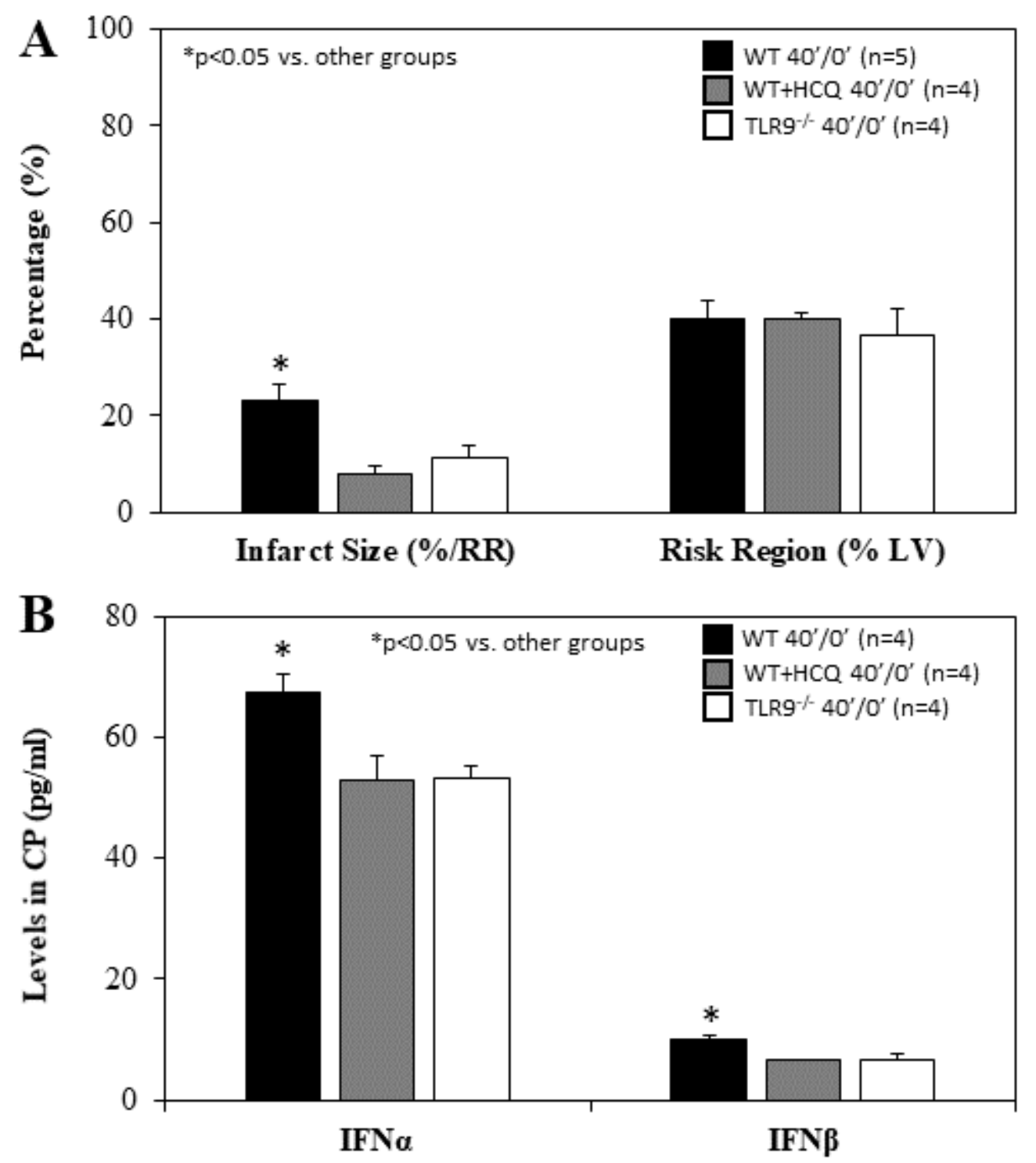

Figure 2

Infarct size (IS) was measured as percentage of RR. WT control mice had an IS of $23 \pm 4$ whereas treatment with $\mathrm{HCQ}$, as a $20 \mu \mathrm{g} / \mathrm{g}$ intravenous bolus administered before occlusion, attenuated IS to $8 \pm 2$ vs. control $p<0.05)$. In TLR9-/- mice, IS was $11 \pm 2$, a $50 \%$ reduction from WT control $(p<0.05$, Figure $2 A)$. Levels of IFNa and IFN $\beta$ in CP were significantly lower in HCQ-treated WT mice and TLR9-/- mice than WT control mice (Figure 2B). 
Figure 3.
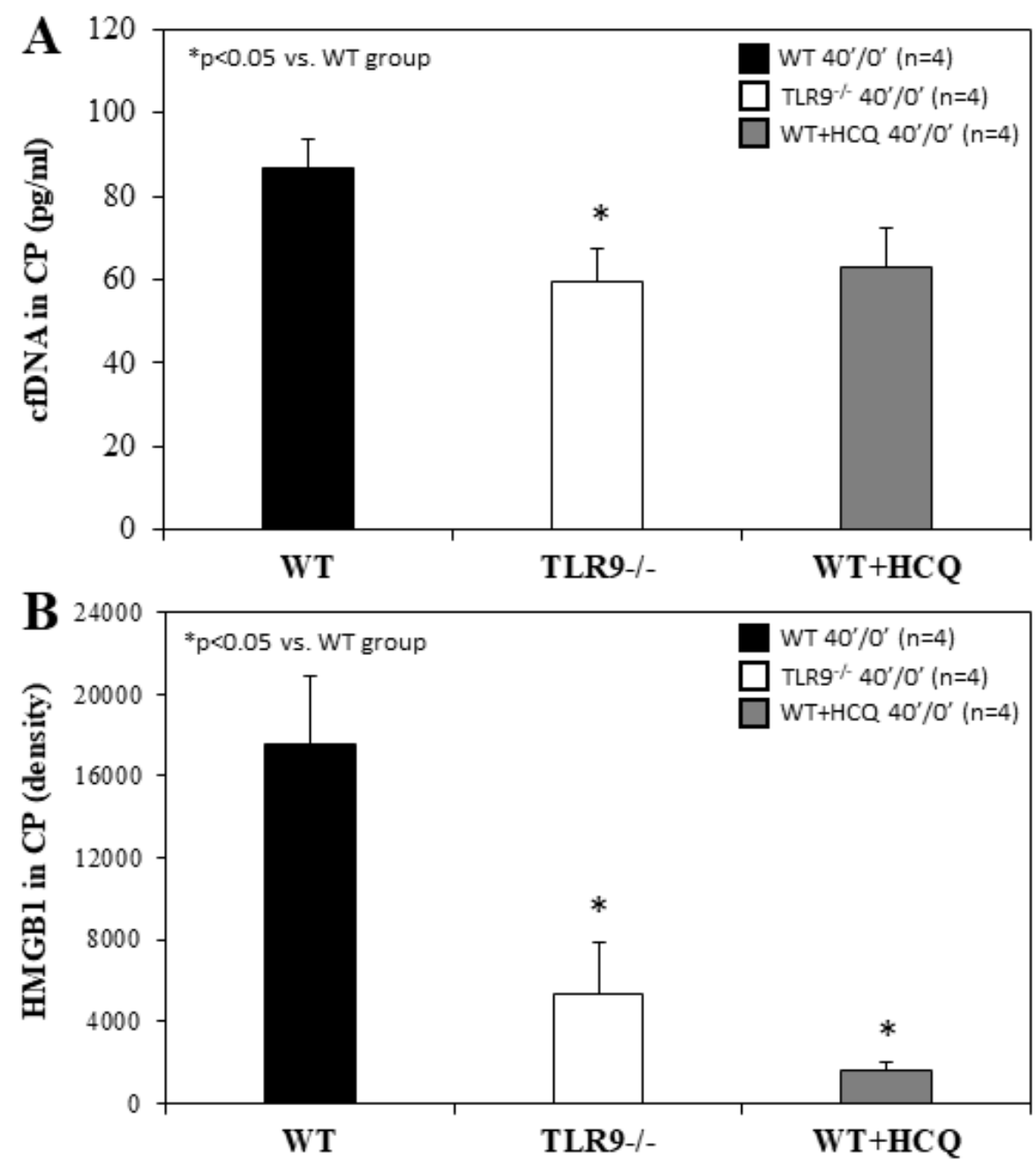

HMGB1

\section{Figure 3}

Cell-free DNA and HMGB1 in CP were also significantly lower in HCQ-treated WT mice and TLR9-/- mice than WT control mice 


\section{Figure 4.}
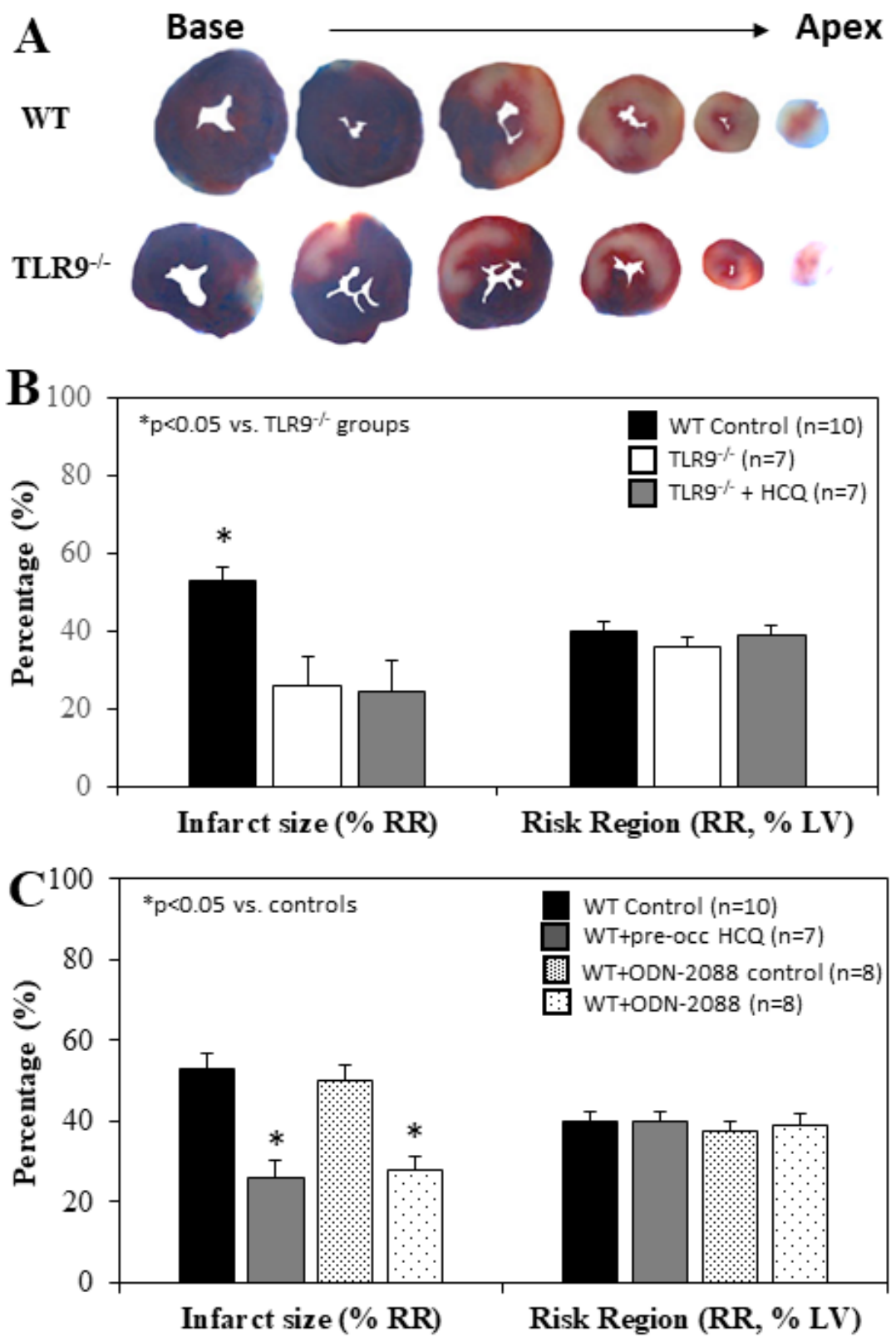

Figure 4

When treated immediately prior to ischemia (IRI pre-ischemic treatment), IS after 60 minutes of reperfusion was significantly attenuated to $26 \pm 8$ in TLR9-/- mice, a $>40 \%$ reduction compared to WT control mice $(\mathrm{p}<0.05)$. HCQ treatment $(20 \mu \mathrm{g} / \mathrm{g})$ did not further reduce the IS in TLR9-/- mice (Figure 4A \& 4B). Pre-treated WT mice with ODN-2088 or high dose HCQ similarly attenuated IS ( $28 \pm 4$ or $26 \pm 2$, 
respectively, vs. corresponding control - ODN negative or PBS control $(50 \pm 4 \%$ or $53 \pm 4 \%, p<0.05$. Figure 4C). RR was comparable among the control and treated groups (right column in Figure 4C).

Figure 5.
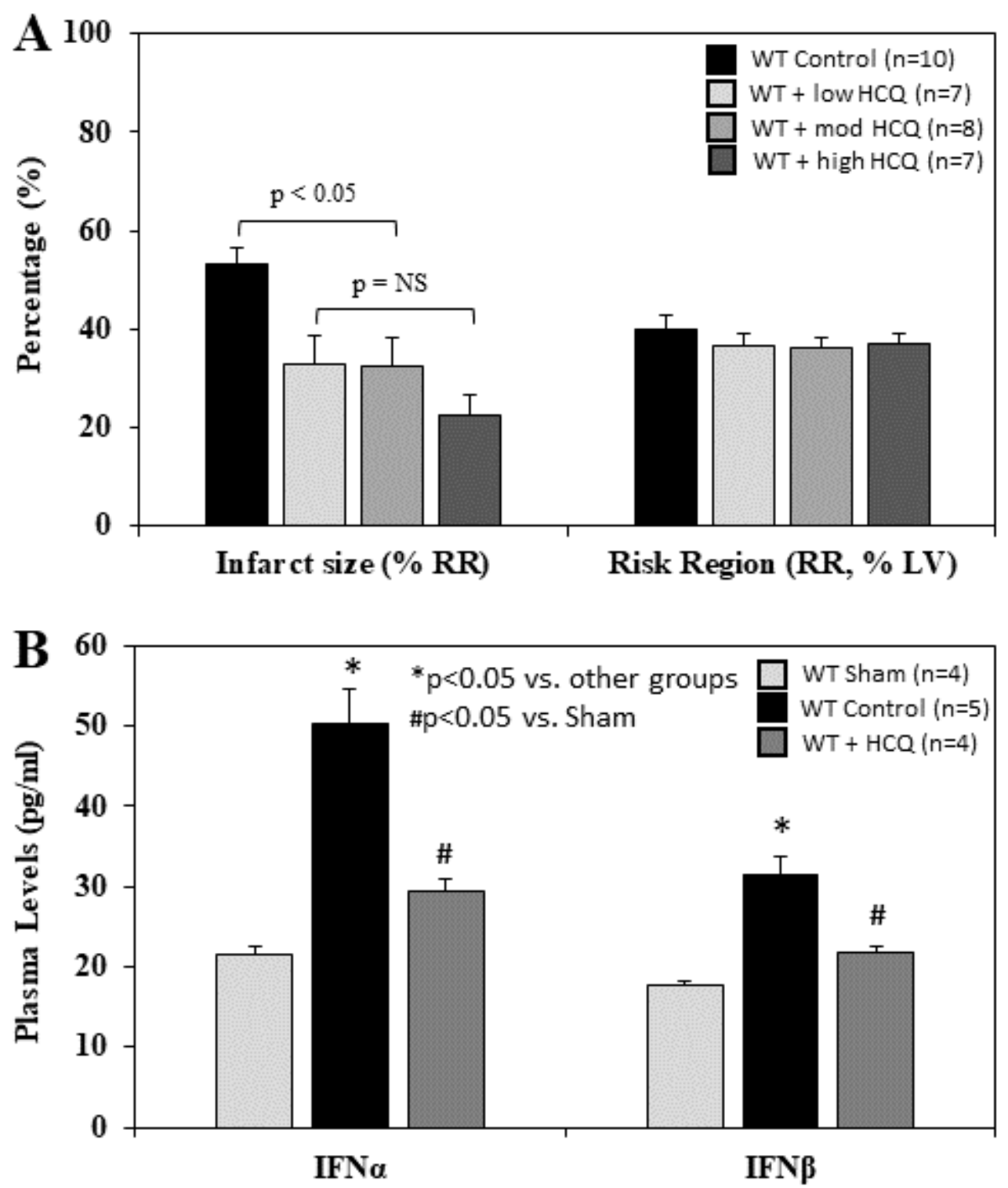

Figure 5

In control mice, plasma levels of IFNa and IFN $\beta$ were significantly elevated at the end of 60 minutes of reperfusion. Levels of IFNa and IFN $\beta$ in HCQ-treated mice (moderate dose) were significantly lower than control mice but remained higher than the control mice (Figure 5B) 


\section{Figure 6.}

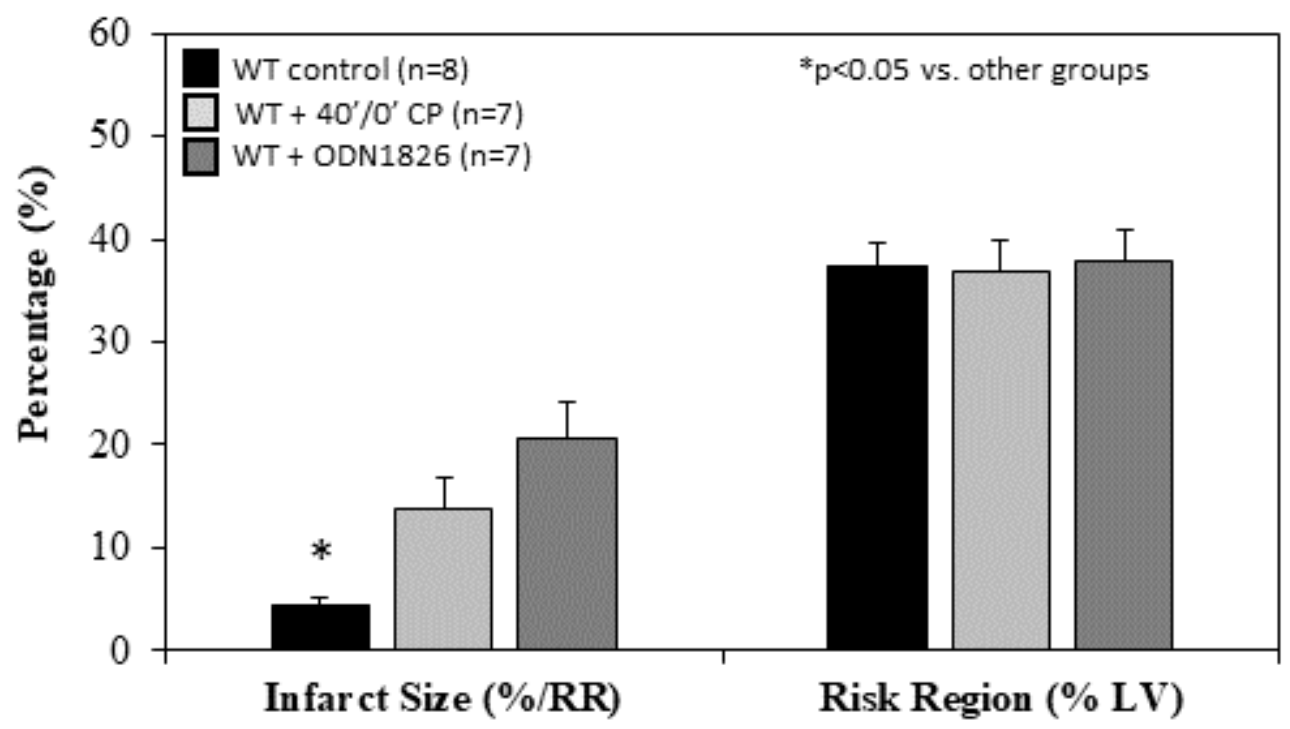

Figure 6

The IS in WT control mice was $4 \pm 1$. CP and ODN-1826 significantly exacerbated IS to $14 \pm 3$ and $21 \pm 4$ respectively ( $p<0.05$ vs. control). There was no statistical difference between $\mathrm{CP}$ - and ODN-1826-treated groups 


\section{Figure 7.}

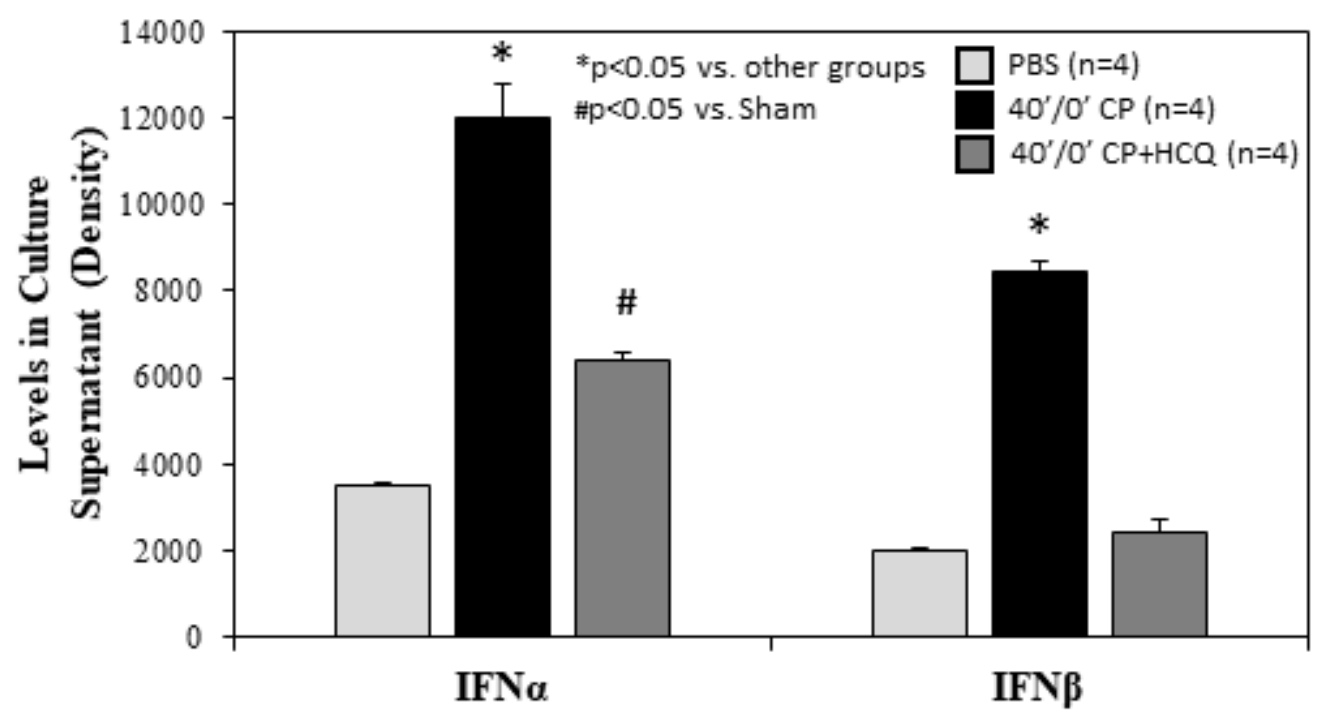

IFN $\alpha$

IFN $\beta$

\section{Figure 7}

$\mathrm{CP}$ stimulated splenic leukocytes to secrete IFNa and IFN $\beta$. The increases in IFNa and IFN $\beta$ levels were were reduced by treatment with HCQ 